\title{
تصميم وتنفيذ برناهج في حسابات إنتاج النسيج
}

إعلاد

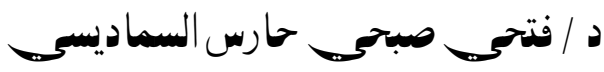

مدرس بقسم الغزل والنسيج والتريكو

كلية الفنون التطبيقية - جامعة دمياط

مجلة بحوث التربية النوعية ـ جامعة المنصورة

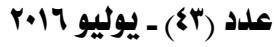




\section{تصميم وتنفيذ برناهج في حسابات إنتاج النسيج}

إعداد
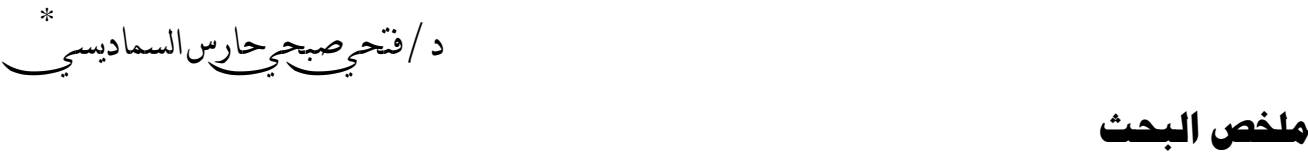

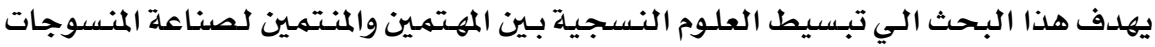

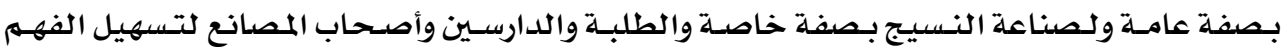

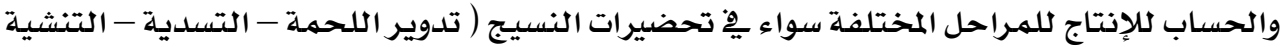

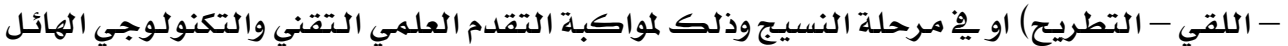

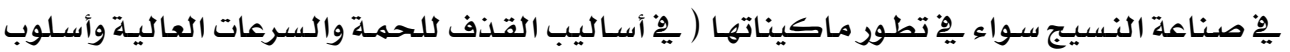

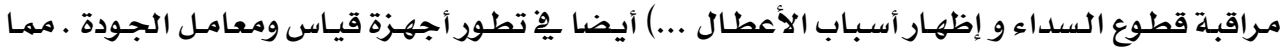

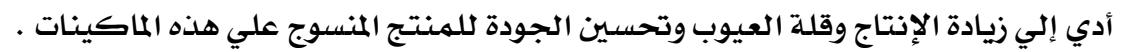
وقد أسميت البر نامج ( FEtexWPC4 ) - ويعمل جيدا علي بيئسة ويندوز - يـدعم اللغتين

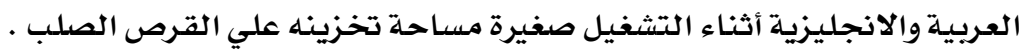
ومن خلال هذا البحث والبرنامج المرفق معـه يمكن عمل الآتي :

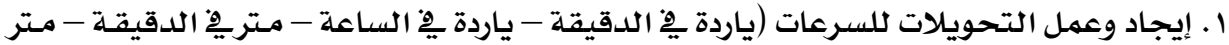

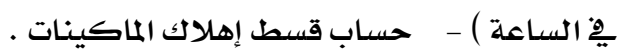
r. تحويل للنمر ( قطن-كتان-ورستد -ولن - مـتري-تكس- دنيير) لاستخدامها ِِ حسـاب الإنتاج

$$
\begin{aligned}
& \text { r. إيجاد إنتاج أقسام ( :دويرات اللحمـة - التسدية و البوث - اللقي ) . } \\
& \text { ع. حساب زمن تغيير مواسير اللحمـة . } \\
& \text { ه. حساب الإنتاج النظري للنول . }
\end{aligned}
$$

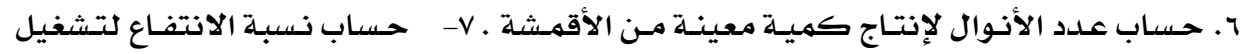

$$
\text { الأنوال . }
$$

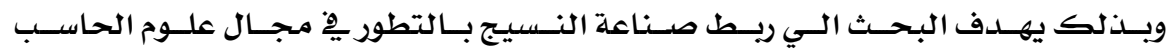

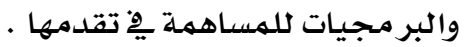


لصناعة النسيج قيمة عظيمة ومكانة متميزة بين باقي الصناعات الحيويـة حيث تمثل أحسد

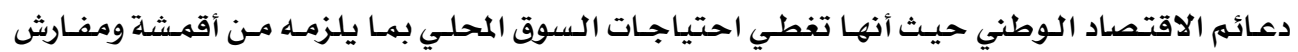

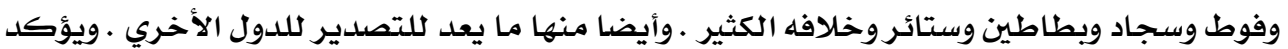

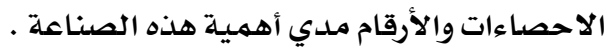

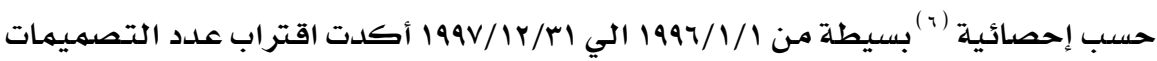

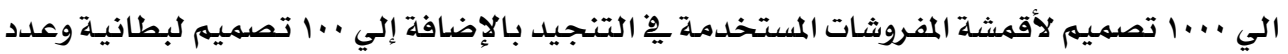

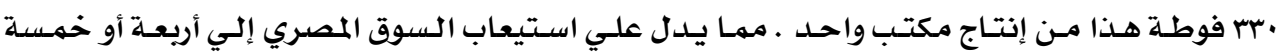
أضعاف من الأرقام السابقة

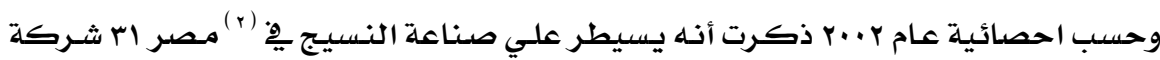

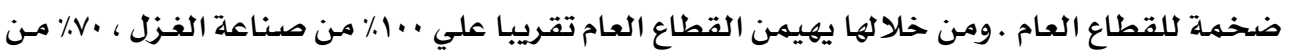

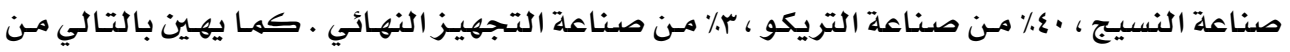

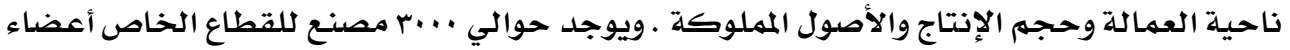

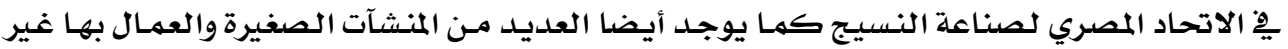

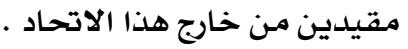
كما يهيمن القطاع الخاص علي مجال صناعة الأقمشة التريكو والملابس .

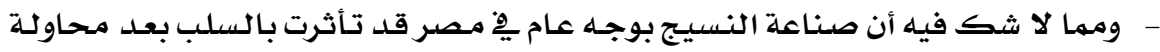

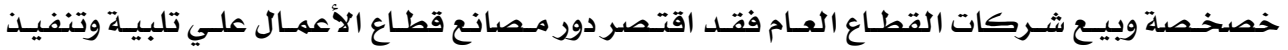

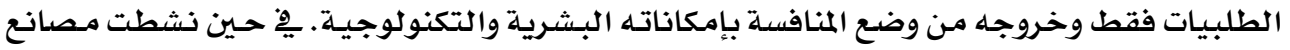

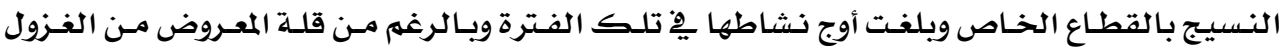

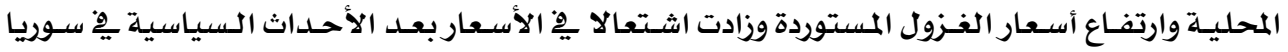

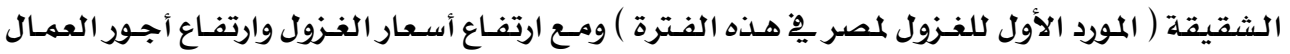

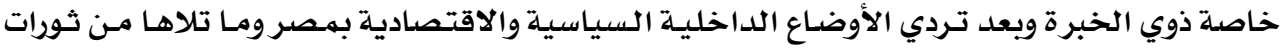

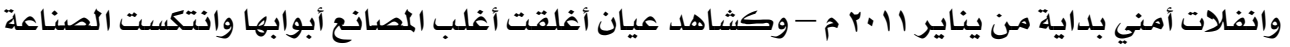

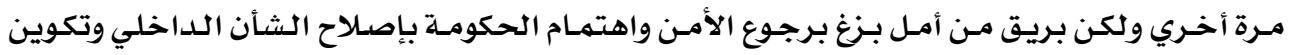

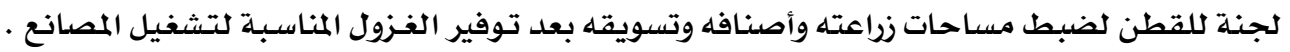

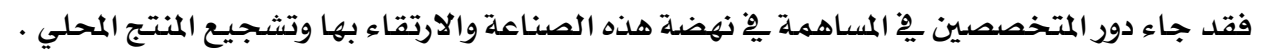
ويجب أن تسعي شركات النسيج ِِّ إنتاج أصنافها علي تحقيق المواصفات القياسية الدوليـة

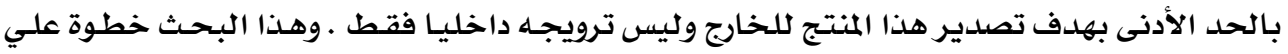

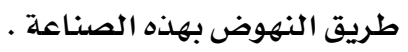




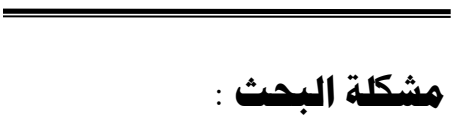

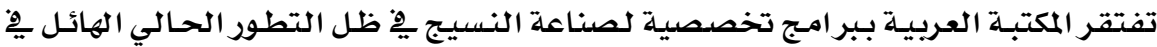

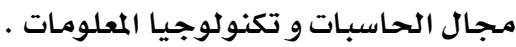

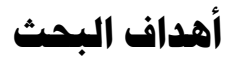

ا ـ إثراء المكتبـة العربيـة وخاصسة للتخصصـات الصناعية التطبيقيـة مثل صناعة النسيج تحديدا

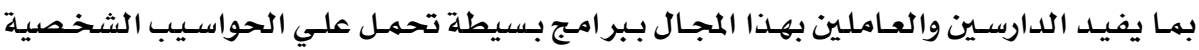

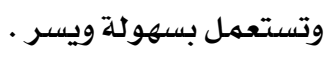

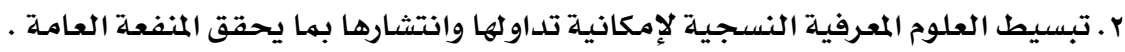

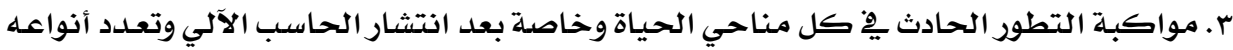

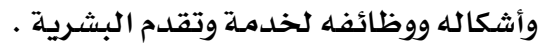

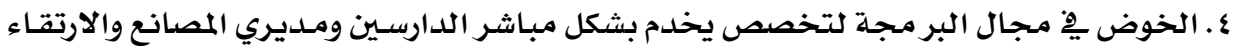

$$
\text { بشأن المهنة . }
$$

فروض البمث :

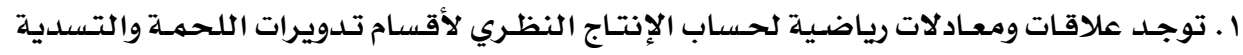

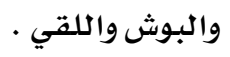

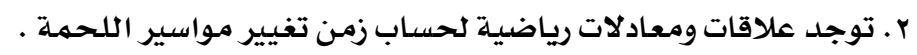

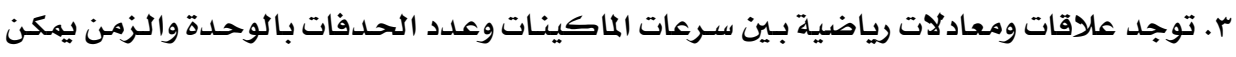

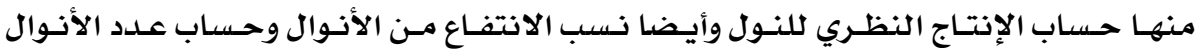

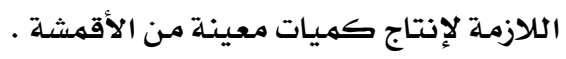

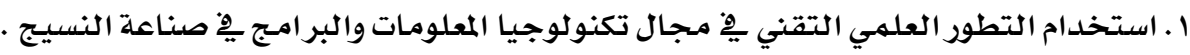

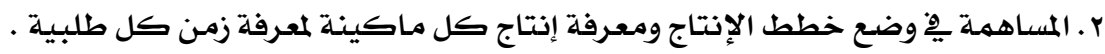

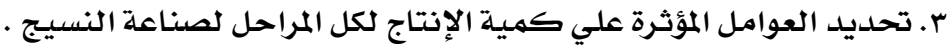

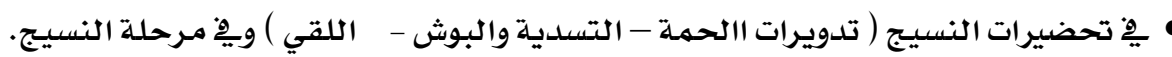

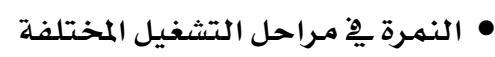

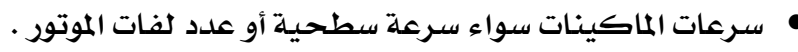

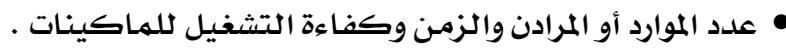

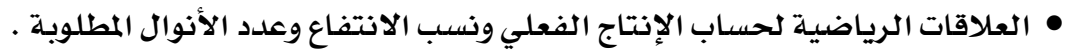




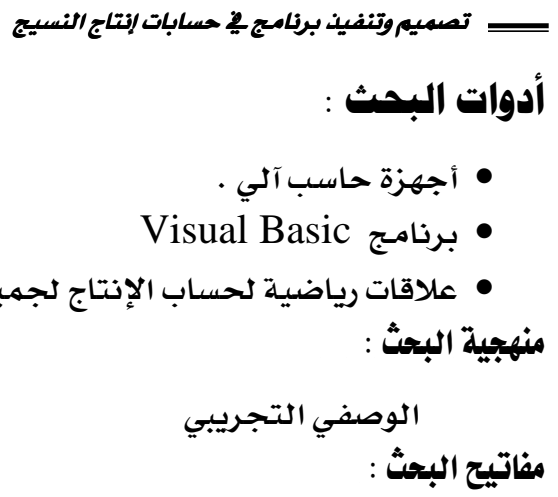

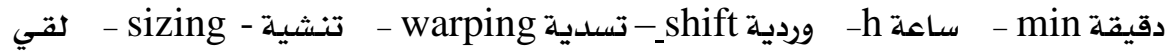

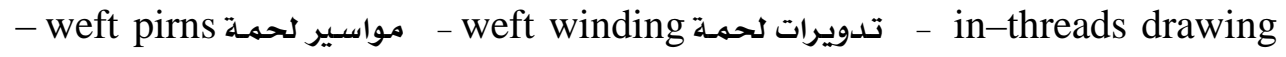

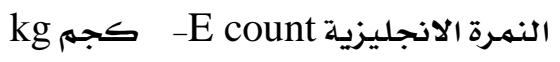

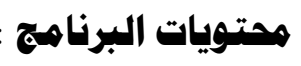

FEtexWPC4 : الاسه المختصر المقترح للبرنامج

يحتوي البرنامج علي ع أجزاء مorms

• الصفحة الأولي للبرنامج :

ويوضحها شكلي رقم ( اوr ) : الواجهة الرئيسية للبرنامج تحتوي علي :

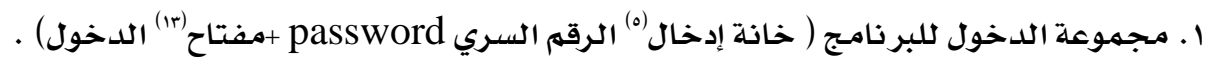

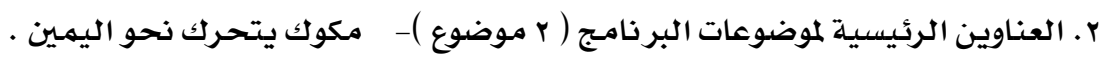

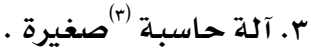

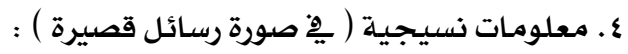

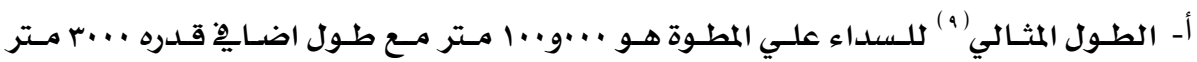

$$
\text { كتعويض الفاقد . تلبول }
$$

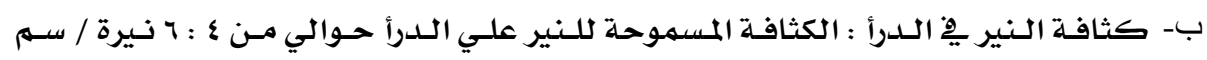

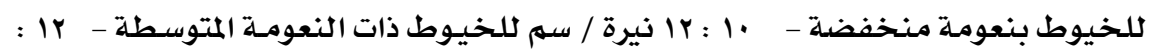

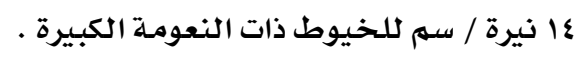

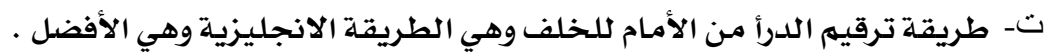

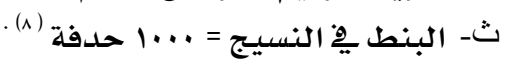

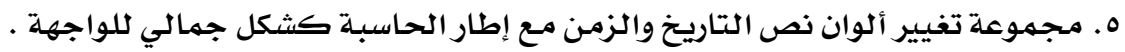

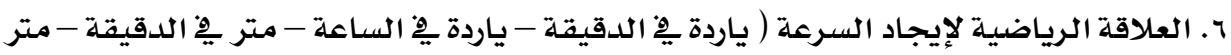

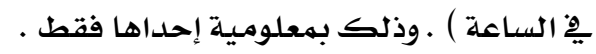

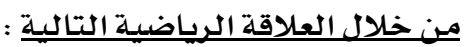

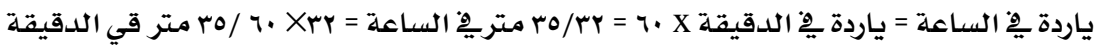




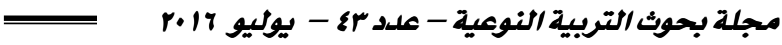

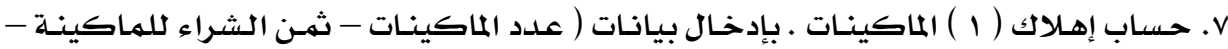

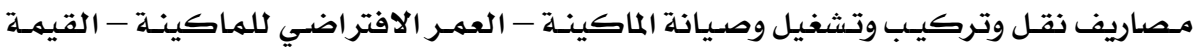

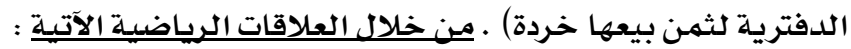

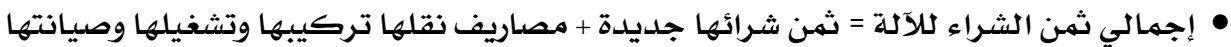

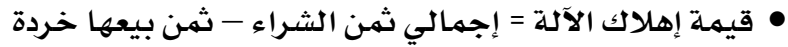

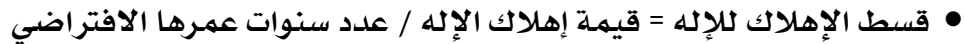
• قسط إهلاك الآلات = قسط إهلاك الآلة الواحدة X عدد الآلات

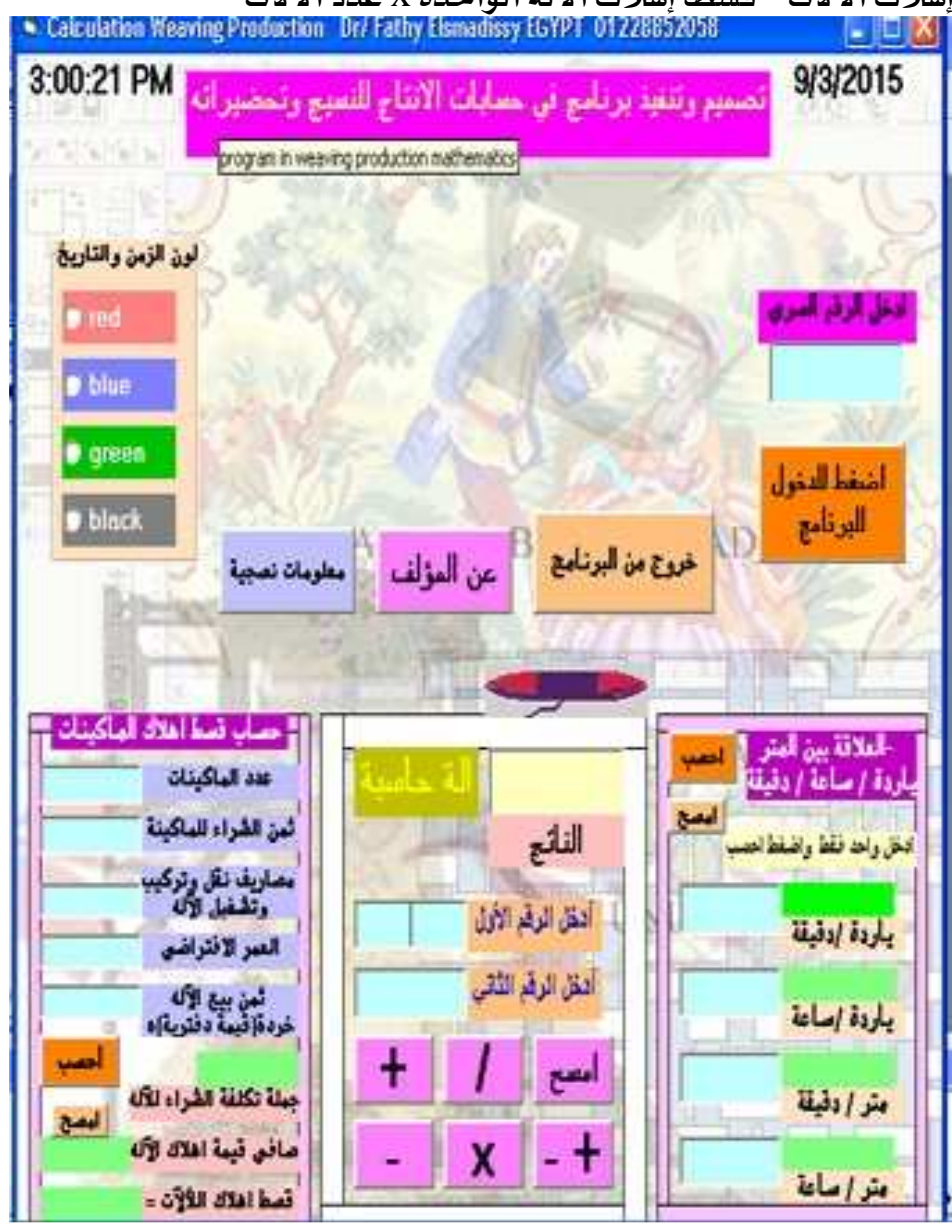

شكل رقم ( 1 ) يوضح الواجهة الرسومية للبرنامج

• الصفحة الثانية للبرنامج :

خاصة بحساب إنتاج أقسام تلدويرات اللحمة - التسدية والبوث - اللقي 
ويوضـحها شـكل رقـم(r) وتعتـبر النهـرة مـن المــــلات العامسة لكـل مـن تــويرات اللحمهـة

$$
\text { والتسدية والبوش. }
$$

ا. تدويرات اللحمة : و بها مجموعة إدخال ومجموعة مخرجات كالتالي :

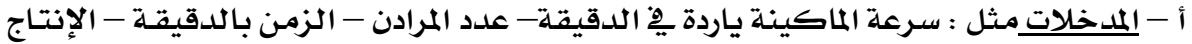

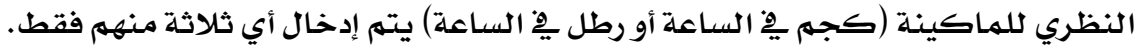

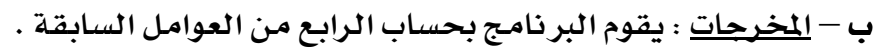

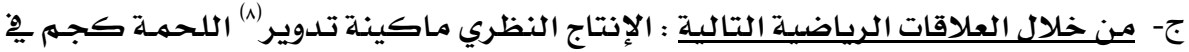

الساعة

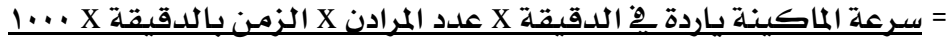

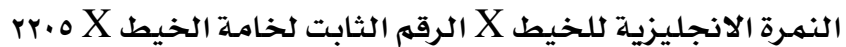

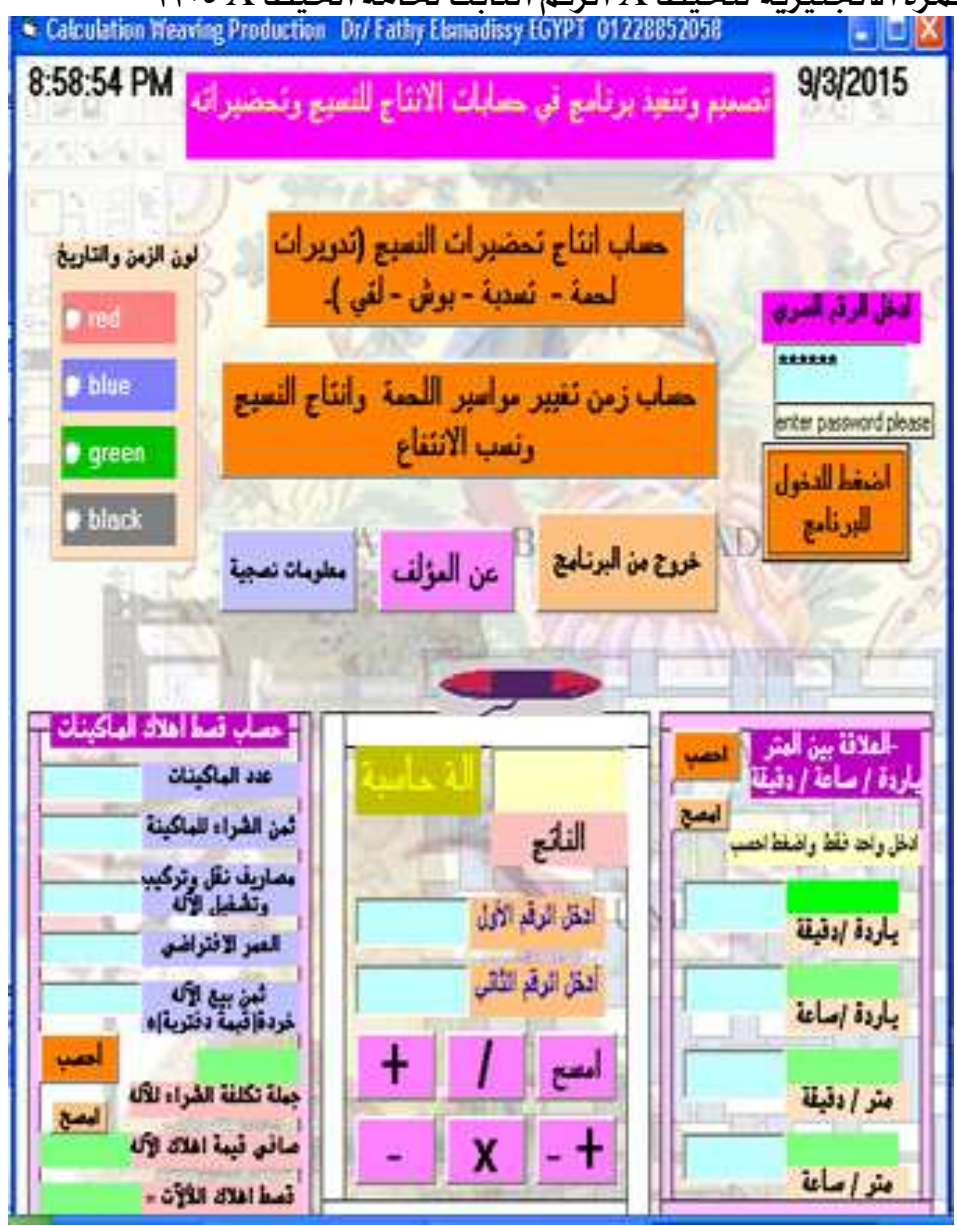

شكل رقم ( r ) يوضح الواجهة الرسومية للبرنامـج بعد إدخال الرقم السري 


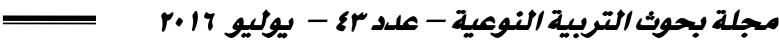

ا ـ التسلدية و البوش : و بها مجموعة إدخال ومجموعة مخرجات كالتالي :

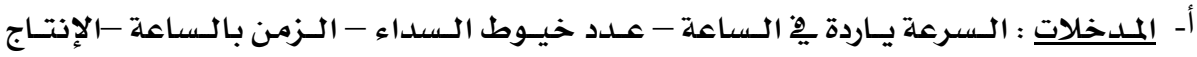

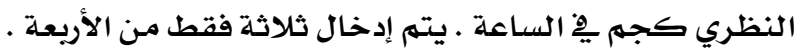

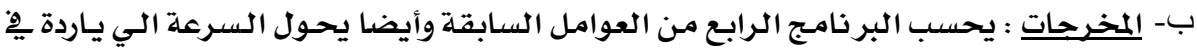

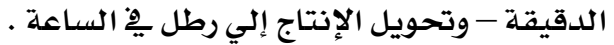

ت- من خلال العلاقات الرياضية التالية :

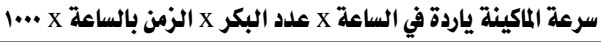
الإتتاج النظري لماكينة التسدية (ل) كجم في الساعة =

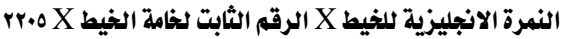

أيضـا من خلال العلاقات الرياضيـة التاليـية :

سرعة الماكينة ياردة في الدقيقة x عدد قتل السداء x الزمن بالدقيقة x x....

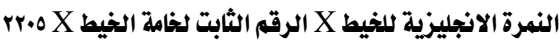

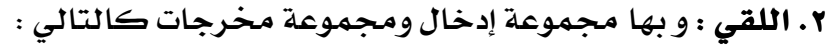

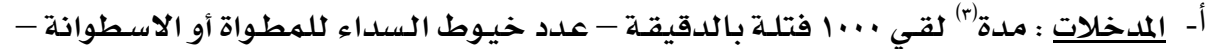

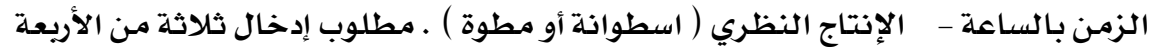

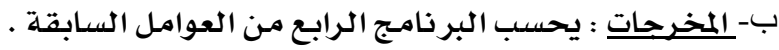

ت-من خلال العلاقات الرياضية التالية :

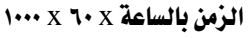

الإتتاج النظري اسطوانة أو مطوة في (v) الساعة =

عدد خيوط السلداء X مدة لقي .... فتلة 


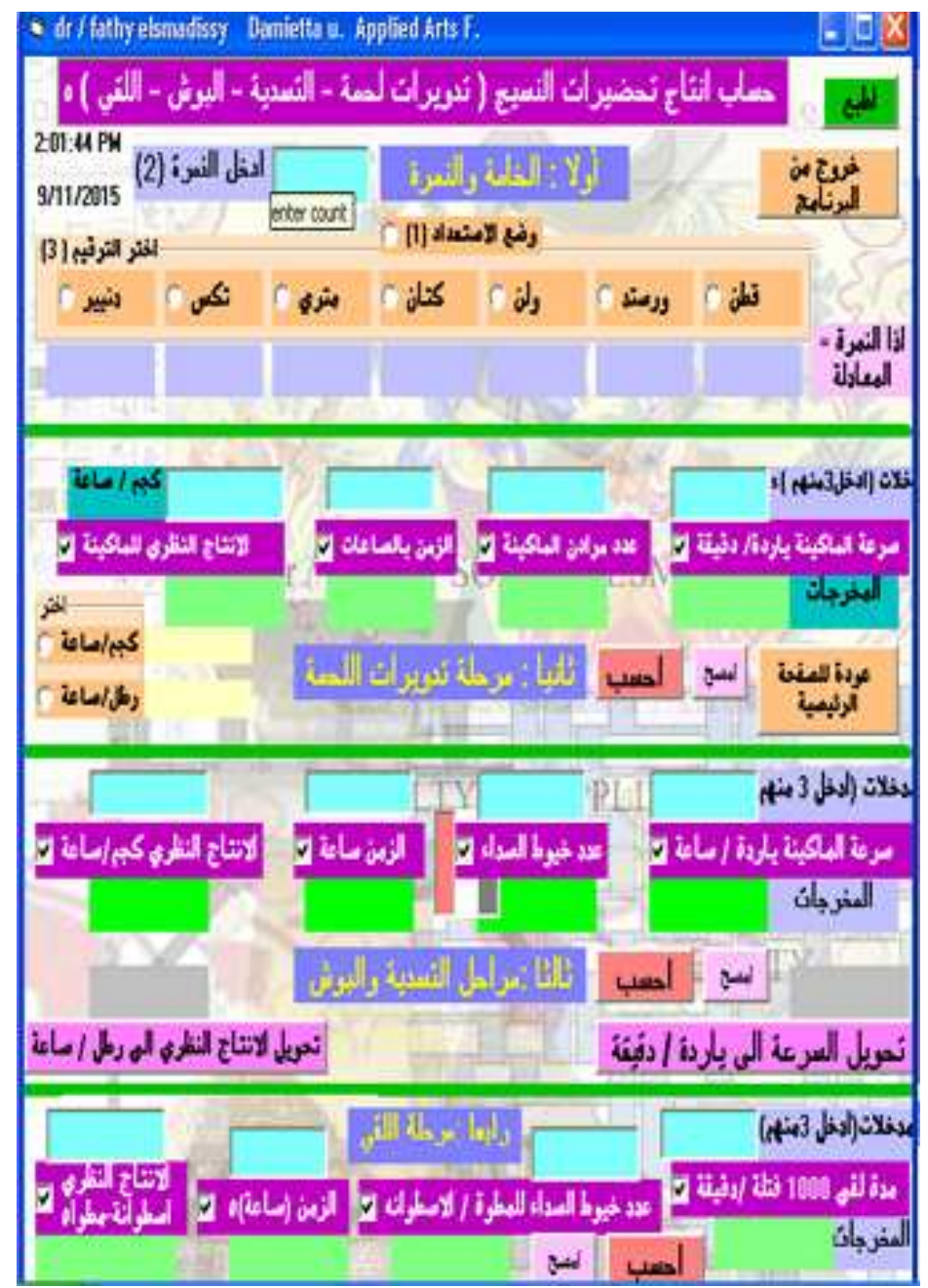

شكل رقم ( r ) يوضح برنامج حساب إنتاج ( تدويرات اللحمة - التسدية والبوش - اللقي )

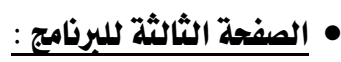

خاصة بحساب زمن تغيير مواسير ومواكيك اللحمة علي النول - حساب الإنتاج النظري

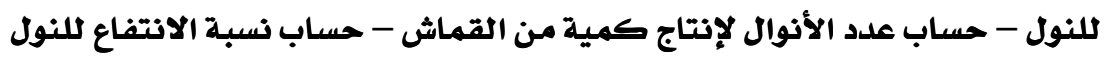

ويوضحها شكل رقم ( ع) :

ا. حساب زمن تغيير مواسـير ومواكيك اللحمـة علي النـول: و بها مجموعة إدخـال ومجموعة

مخرجات كالتالي : 


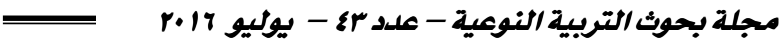

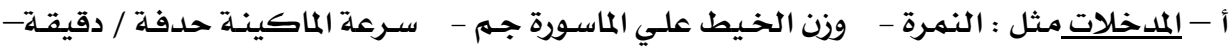

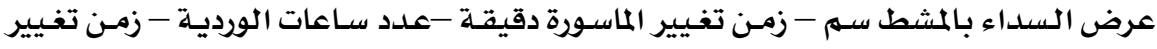

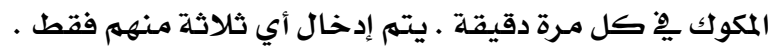

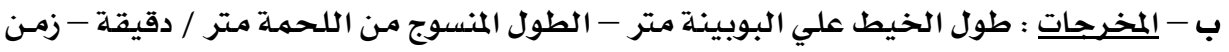

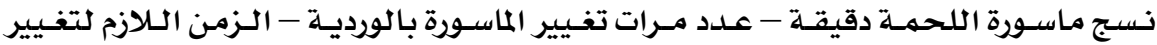

الماسورة بالدقيقة والسـاعة.

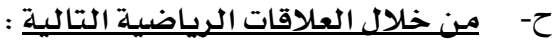

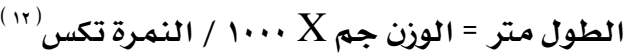

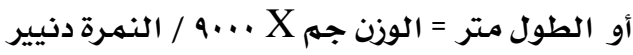

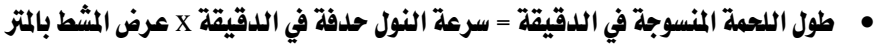

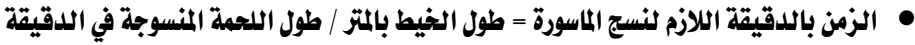

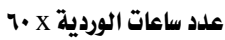

علد مرات تفيير (") ماسورة اللحمة في الوردية = (زمن نسج الماسورة بالدقيقة + زمن تفيير الماسورة بالدقيقة )

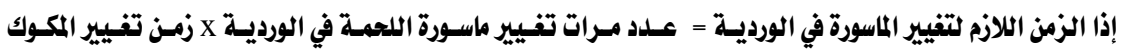

بالدقيقة في كل مرة

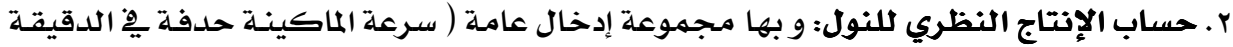

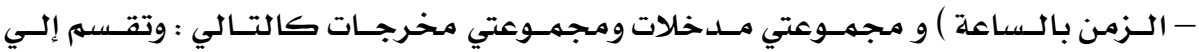

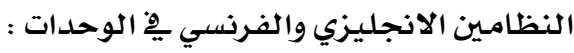

أولا : بوحدات النظام الانجليزي : الانيزي

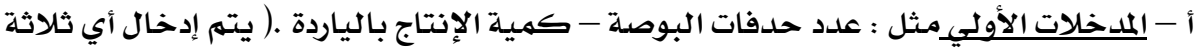

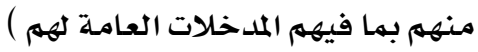

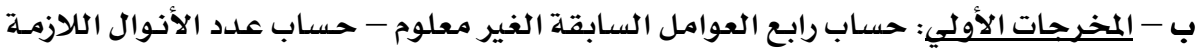

لإنتاج كمية ( يتهم إدخالها بالياردة ) 
الدئ

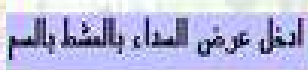

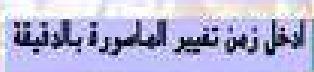

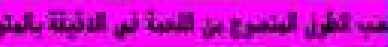

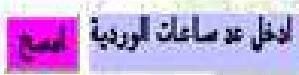

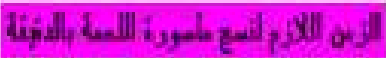

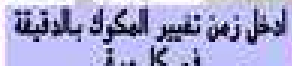

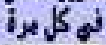

Isid

بالبران

بالثر



الإنتائر

$\%$

\section{المزلن}

\section{دفية \\ ماءئ}

تصن

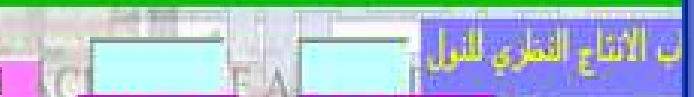

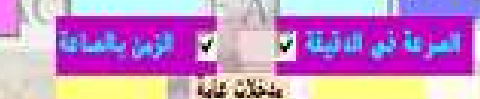

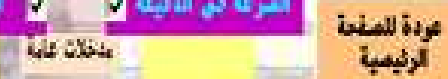

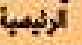

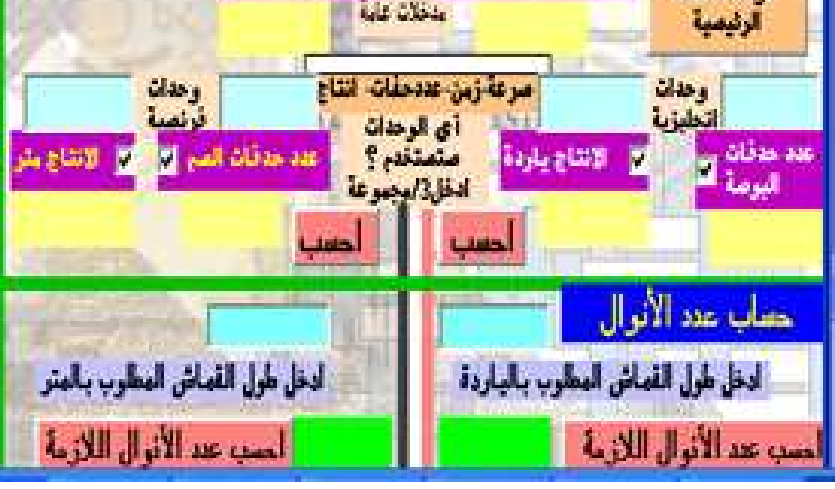

شكل رقم ( ع ) يوضح برنامج حساب زمن تغيير مواسير اللحمة والانتاج النظري للنول

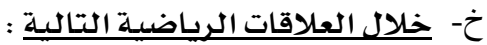

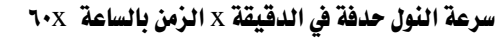

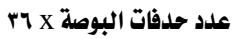

كميــــة القماش بالياردة

إنتاج النول في الساعة X الزمن حساب عدد الأنوال (^) = 
ثانيا : بوحدات النظام الفرنسي :

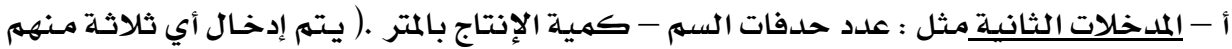

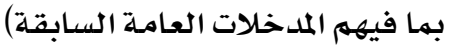

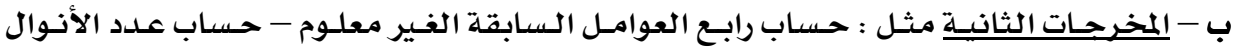

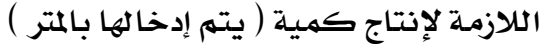

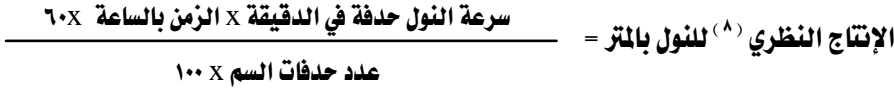
خلال العلاقات الريـاضيـة التتاليـية :

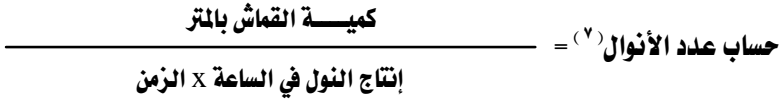

r. حساب نسب الانتفاع للنول: و بها مجموعة إدخال عامـة ( الإنتاج الفعلي للنول ) أولا : بوحدات النظام الانجليزي : الانبات

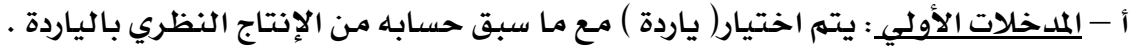

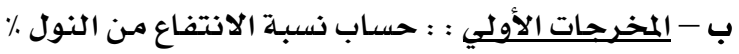
ثانيا : بوحدات النظام الفرنسي :

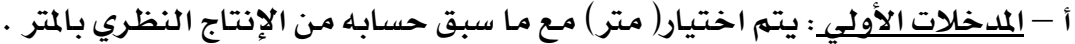

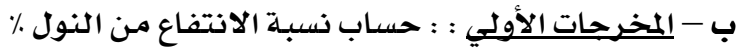
من خلال العلاقات الرياضيـة التالية لكليهما :

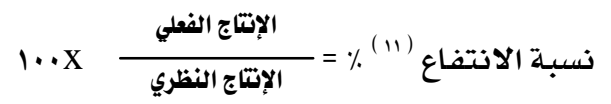

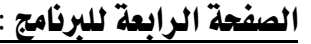

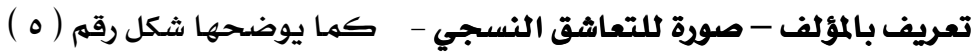

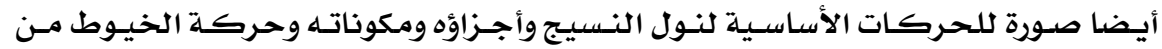

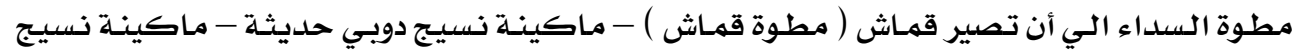
جاكارد حديثة . نتائج البمث : يمكن استخدام البر نامجر المرفق بالبحث :

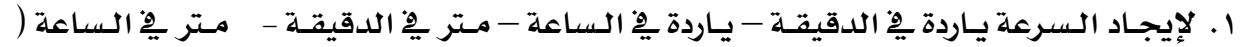

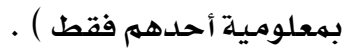

r. . لحساب قسط إهلاك الماكينات بمعرفة ثمن شرائها ومصاريف تشغيلها وعمرها الافتراضي . 


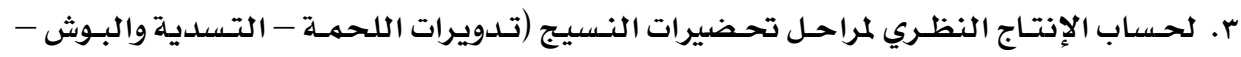
اللقي.

ع. لحساب زمن تغيير مواسير اللحمة يِّ الوردية يِّ الأنوال المكوكية.

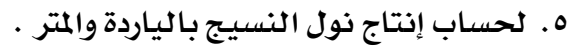

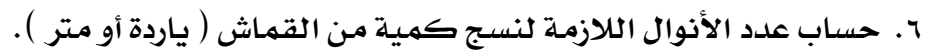

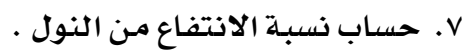

1. التعرف علي بعض المعلومات النسجية وأجزاء وحركات ملات النول والتعرف علي بعض الماكينات

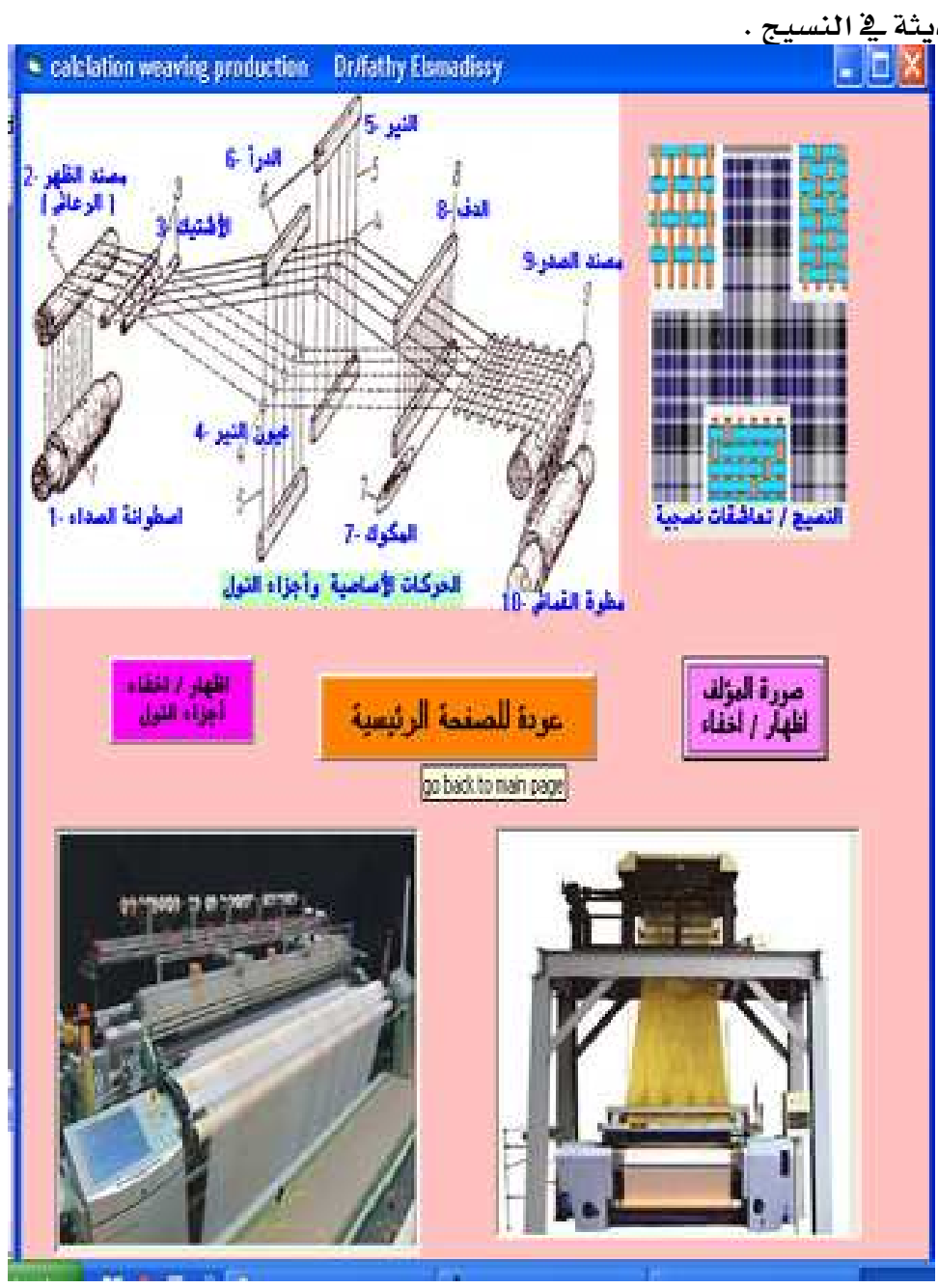

شكل رقم ( 0 ) يوضح نسيج + تعاشقات نسجية - الحركات الأساسية وأجزاء النول-

ماكينات نسيج دوبي وجاكارد 


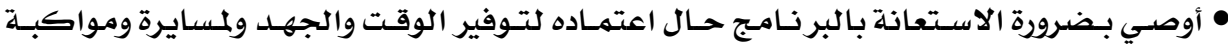
التقدم التقني والفني يف جميع مجالات الحياة وخاصدة صناعة النسيـج ·

• الاهتمام بتدريس البر مجلة ِِ التخصصات العملية بـالجامعات والمعاهد العليا .

• تشجيع البححث العلمي وخاصة المشـروعات التنافسية بين عدة تخصصات تريطها ببعضها أعمال

مشتركة

المراجع :

ا. أحمد شوقي علي وآخرون - التنظيم الصناعي للغـزل ه سـنوات - وزارة التربيـة والتعليهم - قطاع الكتب

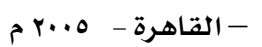

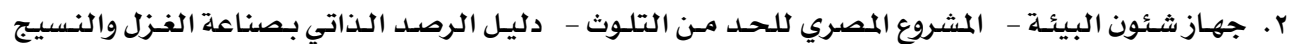
r..r

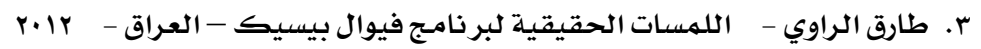

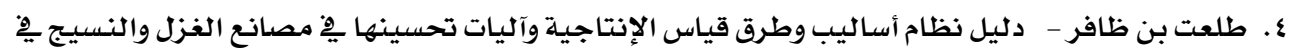
الدول العربية - الصندوق العربي للإِنهاء الاقتصادي والاجتماعي - ع... م م

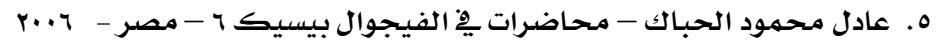

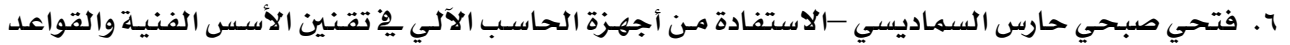
التطبيقيـة لتصميهم أقهـشة المفروثـات المنفـذة علسي أنـوال الجاكـارد .( رسـالة مـاجستير) - كليـة الفنـون التطبيقية - جامعة حلوان - 1999 م .

V. فيروز أبـو الفتـوح الجمـل محاضـرات يفوفحص وتحليـل المنسـوجات - كليـة الفنـون التطبيقيـة - جامعـة

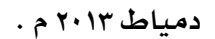
1. محمد جمال عبد الغفور - اقتصاد صناعي وتكاليف ץ - كلية التربية - جامعة المنصورة

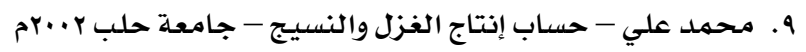
• ا.مذذكرات يِّ اقتصاديات تصميهم المنسوجات - كلية الفنون التطبيقية - جامعة دمياط

11. A.N.M. Masudur Rahman \& Md.Ruhul Amin - Efficiency Analysis In Rapier Loom - International Journal of Basic \& Applied Sciences - Ahsanullah University of Science and Technology- Love Road, Tejgaon I/A, Dhaka-1208, Bangladesh - 2011 .

12. tables and units for the textile industry sulzer ruti

13. Http://hoaxer4ever.wordpress.com. 
= تصميروتنفيذ برزامج مِ حسابات إنتاج النسيج

Designing and Executing Program in Weaving Production Calculations FEtexWPC4

Dr. (lec.) / Fathy Sobhy Haris Elsmadissy•

\section{Abstract}

This search aims simplification the textile sciences, generally for the textile industries ,specially the weaving industries and to facilitate understanding and account for production calculation for students, and factory owner ,interested and people who belonging to this career with its variety processes such as weaving preparation ( weft winding - warping sizing - threads drawing - in )and weaving processes to cope up with massive advance in the technical, scientific and technology in weaving industries such the development in machines ( weft picking systems ,high speeds, the warp control system , and showing crashes places ...) also the development of quality control sets and laboratories .

All of this due to production increasing, reduce the defects and improve the the weaving products quality which carried out on this machines .

I named this program (FEtexWPC3). It work well in windows, work in Arabic and English languages , little storage area on hard disk

From this search and its program we can do the next items:

1-make conversion for speeds (yard/min -yard/h - meter/ min- meter/ h).

2-calculate premium of depreciation for machines .

3-yarn count conversion ( cotton -worsted- woollen -metric - tex denier ) to use it in another calculations .

4-calculate the theoretical production for (weft winding - warping -sizing - threads drawing - in ) .

5-calculate the time which needed to change weft pirns .

6-calculate the theoretical production for looms ( yard- meter) .

7-calculate how many looms was needed for weaving a certain amount of fabrics.

8-calculate the efficiency rate for looms.

So that this search aims to connect weaving industries with the development on the computer sciences and programs to help it to be advanced.

* Spinning, Weaving and Knitting Dept . Faculty of Applied Arts Damietta University 